\title{
Growing into adulthood-a review on sex differences in the development of sociality across macaques
}

\author{
Federica Amici ${ }^{1,2,3} \cdot$ Lars Kulik $^{1,2} \cdot$ Doreen Langos $^{1,2} \cdot$ Anja Widdig $^{1,2}$
}

Received: 18 April 2018 /Revised: 28 November 2018 / Accepted: 4 December 2018 / Published online: 25 January 2019

(C) The Author(s) 2019

\begin{abstract}
Preferential affiliative relationships, or social bonds, play a crucial role in primate social life, but little is known about their development. Here, we review macaque studies investigating the social development of both sexes. Firstly, we highlight the emergence of sex differences in mother-offspring bonds, as macaque mothers form stronger bonds with daughters, while being more aggressive towards sons, possibly contributing to maintain female philopatry and/or male dispersal. Secondly, despite paternity uncertainty, we discuss studies reporting that fathers of several macaque species preferentially engage with their offspring, but less than mothers and only in periods of high infant mortality. Thirdly, we show that immature females, the philopatric sex in macaques, already form stronger bonds with close maternal kin than immature males, mirroring social patterns during adulthood. However, this bias seems not caused by kin availability, as kin availability is similar for both sexes prior to male dispersal. Moreover, immature males might preferentially affiliate with paternal kin over non-kin, possibly because of lower maternal integration in their maternal family and/or in preparation of dispersal. Fourthly, we discuss how immature females engage in grooming and proximity with female partners as they grow older, while immature males preferentially interact with adult males and peers, playing more than females from early on. Finally, we show that most developmental changes in sociality happen around 2-3 years of age, probably representing a milestone in macaque social development. We conclude that sex differences in sociality emerge early in development and increase through time, with sexes gradually growing into their adult roles.
\end{abstract}

Keywords Social development $\cdot$ Macaques $\cdot$ Primates $\cdot$ Ontogeny $\cdot$ Sociality $\cdot$ Aggression

Communicated by P. M. Kappeler

This article is a contribution to the Topical Collection - An evolutionary perspective on the development of primate sociality - Guest Editors: Federica Amici and Anja Widdig

This paper is dedicated to our kids.

Anja Widdig

anja_widdig@eva.mpg.de

1 Jr Research Group of Primate Kin Selection, Department of Primatology, Max-Planck Institute for Evolutionary Anthropology, Deutscher Platz 6, 04103 Leipzig, Germany

2 Institute of Biology, Faculty of Life Science, University of Leipzig, Talstraße 33, 04103 Leipzig, Germany

3 Department of Comparative and Developmental Psychology, Max-Planck Institute for Evolutionary Anthropology, Deutscher Platz 6, 04103 Leipzig, Germany

\section{Introduction}

Sociality plays a crucial role in primate life. Although primates mainly form preferential affiliative relationships (hereafter social bonds, see Silk 2007) with their close relatives (see Silk 2002a, for a review), such bonds can also occur among unrelated individuals (see Silk 2002b, for a review). Recently, several studies have shown that the strength and stability of these affiliative relationships significantly increase primate fitness. For example, the quality of social relationships positively affects females' (Engh et al. 2006a, b; Crockford et al. 2008; Wittig et al. 2008) and males' ability to deal with stressful events (Young et al. 2014) and considerably increases females' longevity (Silk et al. 2010). Social bonds also enhance individual reproductive performance (Schülke et al. 2010; Kulik et al. 2012; Langergraber et al. 2013) and increase infant survival (Silk et al. 2003, 2009). Even in humans, social integration significantly enhances longevity, as well as physical and mental health (e.g. Olsen et al. 
1991; Eriksson et al. 1999; Berkman and Glass 2000; Cacioppo and Hawkley 2003; Berkman et al. 2004; Smith and Christakis 2008; Holt-Lunstad et al. 2010).

While sociality and fitness have recently influenced the focus of many primate studies (see Kappeler et al. 2015), it is time to summarize what we actually know about the development of social bonds during ontogeny. A comprehensive understanding of such topic would come from studies covering the entire period from birth to sexual maturation, describing the development of several social behaviours (e.g. bonding behaviours, like grooming, shared spatial proximity, coalitionary support, play; but also behaviours negatively affecting bonding, like aggression, or behaviour repairing relationships, such as reconciliation) and discussing differences in social development in relation to the most important social partners, such as mothers, fathers, other kin and peers. However, available data from several primate species are often limited in this respect.

Firstly, they often cover only short time frames, failing to include infants, juveniles and adolescents (here respectively defined as nutritionally dependent offspring, weaned offspring who have not yet entered puberty, and offspring in puberty; see Pereira and Altmann 1985; Lonsdorf 2017). Secondly, few behaviours are usually observed in developmental studies. Aggressive behaviour, for instance, serves an important function in social relationships (e.g. Fraser et al. 2008), but they are only rarely studied from a developmental perspective. Thirdly, social relationships can critically vary depending on the identity of the focal sex and the social partners involved. For example, members of the philopatric sex may form closer bonds with their mothers given their permanent association, while members of the dispersing sex may form stronger relationships with same-sex peers likely to migrate around the same time. In general, individuals of the philopatric sex have close kin available as long-term partners; accordingly they are typically more closely related; hence, the philopatric sex is expected to form stronger social bonds than the dispersing sex (Di Fiore 2003; Clutton-Brock and Lukas 2012; see Widdig et al. 2016).

Even more important, however, is perhaps whether primate sociality follows different developmental trajectories in males and females. Given that primates are only weakly sexually differentiated at birth, sex differences in social behaviour mostly develop during the postnatal period (e.g. Lee 1984; Bentley-Condit 2003; Nguyen et al. 2012). If sex-specific social behaviours are an important aspect of adult behavioural competence, and hence linked to higher reproductive success, the proximate mechanisms underlying the development of sex-specific social behaviours become targets of selection (see Meredith 2013). Moreover, sexual selection will favour sex differences in social development, with females developing more caretaking and affiliative behaviour and males showing more competitive and aggressive behaviour (see Lonsdorf and Ross 2012). Depending upon their sex, immatures may therefore benefit from changing their social behaviour through development by increasing their future adult performance (i.e. practicing behavioural patterns typical of adulthood), without reducing their actual chances to survive. While philopatric females, for instance, could be expected to increase their frequency of affiliative behaviours, especially toward longterm social partners such as maternal kin, dispersing males could be expected to increase the frequency of social behaviours toward other males and age peers, with whom they either compete with or will likely migrate (see below).

To gain a comprehensive view of primate social development, we will extensively review literature to discuss how affiliative and aggressive behaviours develop from birth to sexual maturation depending on the social partners, with a special focus on the emergence of sex differences. We will especially draw attention on the results of longitudinal studies on free-ranging populations, including comprehensive genetic and demographic data, as these may provide a more exhaustive and representative picture of primate social development. We will, however, restrict our review to the genus Macaca (only referring to other primates when relevant), as with more than 20 species it represents a socio-ecologically highly diverse taxon (reviewed in Thierry 2007). All macaque species live in multi-male male-female groups, with males dispersing from their natal group around puberty (Gouzoules and Gouzoules 1987; Schülke and Ostner 2012) and females remaining in their natal groups (Gouzoules and Gouzoules 1987). Accordingly, macaque groups are characterized by maternally related females organized in matrilines. However, striking variations are apparent, for instance, in male ability to gain or maintain dominance and monopolize fertile females, resulting in different male reproductive skews (compared in Engelhardt et al. 2017). This has important consequences for the kin structure of social groups, as differences in male reproductive performance and ability to maintain high dominance lead to differences in the availability of paternally related peers (Widdig 2013). Moreover, both sexes mate with several partners, but mating relationships vary from regular transition of partners to prolonged mate guarding (Thierry 2007). Several macaque species are strictly seasonal breeders, while others give birth year-round or have several birth peaks (reviewed in Estrada and Estrada 1976; Smith 1984; Marty et al. 2017b). Finally, and perhaps most crucially, macaque species exhibit social relationships varying from intolerant or despotic (e.g. rhesus, Macaca mulatta, and Japanese macaques, M. fuscata), to more tolerant or egalitarian ones (e.g. crested macaques, M. nigra, and Tonkean macaques, M. tonkeana), in response to the different qualities of food resources (Thierry 2000). Such a variety of socio-ecological characteristics may have deep effects on the development of social relationships, as we will discuss below. 
In the following sections, we will review the impact of mothers, fathers, other kin or other partners on the social relationships of immature macaques. In particular, we will focus on the developmental aspect of social bonding in male and female macaques throughout their first 4 years of life (representing the approximate period of sexual maturation in macaques; see, e.g. Dixson and Nevison 1997; Zehr et al. 2005). Throughout our contribution, we will highlight the variability of macaque sociality if data are available, we will discuss how the frequency of affiliative and aggressive social interactions change until adulthood in males and females, and we will show how different social circumstances may affect the development of offspring sociality.

\section{The role of mothers in offspring social development}

As in other primates, macaque mothers provide extensive care to their offspring and may thus strongly affect their development (starting as early as in the prenatal stage: see Schülke et al. in this Topical Collection). Consequently, mothers form the strongest social relationships with their offspring (e.g. Schülke et al. 2013). Their mothering styles vary from highly protective to highly tolerant, depending upon the social structure of the species (Thierry 1985; Maestripieri 1994a, b, c, for review see Maestripieri 2018 in this Topical Collection). For example, maternal protection is high in despotic species such as rhesus macaques (Berman 1980b) and pig-tailed macaques (Macaca nemestrina; Maestripieri 1994c), while stumptail macaques ( $M$. arctoides) show low maternal protectiveness and low rejectiveness (Maestripieri 1994c).

Even within the same species, mothering style can vary strongly, with important consequences for offspring independence. In Japanese macaques, for example, infants of protective mothers are less interested in interacting with other social partners, while infants experiencing high maternal rejection initiate more social contacts with other juveniles and adults, suggesting that maternal rejection may promote independence, whereas maternal protectiveness may delay it (Schino et al. 2001; Bardi and Huffman 2002). In addition, parity was suggested to influence mother-offspring relationships in the first few months: in despotic species, for instance, multiparous mothers show higher rates of suckling rejection than primiparous mothers (Japanese macaques: Tanaka 1989) and higher maternal protection when no older sisters are present (rhesus macaques: Berman 1992). The lack of older offspring in primiparous females has even been suggested to influence infant personality (Hooley 1983).

If the development of sociality is affected by the social context experienced, and mothers are extensively present for their offspring, the way mothers behave toward their offspring may strongly affect the way their sociality develops (reviewed in Lonsdorf 2017). Therefore, sex differences in sociality, which have been reported in adults across several macaque species (e.g. Bernstein and Ehardt 1985; Kapsalis and Berman 1996; Cooper and Bernstein 2000; see Ellis et al. 2013), might at least be partially triggered by the differential way in which mothers behave toward sons and daughters. Indeed, a study on Barbary macaques (Macaca sylvanus) showed that mothers of female newborns mainly interact with maternally related females, while mothers of male newborns preferentially interact with females of other matrilines, with the consequence that, by the age of 5 months, daughters stay closer to mothers than sons do (Timme 1995). These sex-specific differences may help daughters to integrate into their matrilines and sons into the more general network of the social group (Timme 1995). Other studies also reported that female juveniles associate with their mothers significantly more than male juveniles do (e.g. rhesus macaques: Missakian 1974; Japanese macaques: Itoigawa 1973; Nakamichi 1989; reviewed in Nakamichi and Yamada 2010).

Mothers also treat infants in a different way depending on their sex, moving and breaking contact more frequently with male rather than female offspring (Japanese macaques: Eaton et al. 1986). After their first year of life, both male and female Japanese macaques decrease the variety of social behaviours exchanged with their mothers (Nakamichi 1989), but males decrease the time spent with their mothers more than females do (Eaton et al. 1986; Nakamichi 1989). Moreover, immature male Japanese macaques bond more with male age peers, especially through social play, preceding peripheralization (Nakamichi 1989). In general, long-term studies reported a consistent bias in mother-daughter affiliative bonds (Missakian 1974; Nakamichi 1989), while less consistent patterns emerged from shorter-term studies (Hinde and SpencerBooth 1967; Eaton et al. 1985; Tanaka 1989; Schino et al. 1995; Brown and Dixson 2000).

In an attempt to comprehensively investigate the effect of mothers on the development of offspring's sociality, a recent study on rhesus macaques assessed both affiliative and aggressive interactions between mothers and their offspring, from birth to sexual maturation. The results confirmed that mothers develop different bonds depending on the sex of their offspring but revealed in addition that the social context matters (Kulik et al. 2016). Firstly, no differences in mothers' investment are apparent, as suckling rates are the same for both sons and daughters (Kulik et al. 2016). This supports previous studies on rhesus macaques demonstrating that milk energy received is similar for both sexes, because sons receive richer milk but daughters more milk (Sear et al. 2009; but see Bercovitch et al. 2003 for similar sex-biased maternal investment). In addition to suckling, mothers have similar probabilities to share spatial proximity or grooming with sons or daughters in the first half year, but the probability of grooming and proximity decreases significantly more for sons than for 
daughters between 6 and 12 months of age (Kulik et al. 2016). In contrast, a different pattern is found with regard to aggression, which is exclusively initiated by mothers. The probability to receive maternal aggression is higher for sons than daughters, within the first year; by that time, affiliative bonding between mothers and sons has already decreased. Similarly, maternal aggression peaks around 2 years of age for daughters, hence considerably later in life. Notably, maternal aggression towards sons largely occur spontaneously (i.e. not as a response to son's precedent behaviour), while daughters receive maternal aggression mainly when trying to handle newborn siblings (Kulik et al. 2016). Furthermore, older maternal sisters and unrelated adult females also direct more aggression toward male than female infants in the first year of life (Kulik et al. 2015b). These results have several potential implications. Firstly, they suggest that maternal aggression toward daughters may promote bonding inversely to the daughters' birth order, so that maternal investment can shift from older to younger offspring to maximize maternal fitness (see Godfray 1995; Crespi and Semeniuk 2004).

Secondly, maternal aggression has a strong negative impact on social bonding (e.g. Hinde and Simpson 1975; Worlein et al. 1988; Nakamichi 2001), so that early maternal aggression toward sons may be the most effective way to inhibit social bonds between sons and maternal family (Kulik et al. 2016). Such rejection may open opportunities that sons (i) search for alternative bonding partners (Kulik et al. 2016), (ii) become independent earlier (Bardi and Huffman 2002) or (iii) even disperse earlier from their natal group. Indeed, there is some indication that male immatures spending less time with their mothers and receiving more maternal aggression disperse earlier from their natal group (Kulik et al. 2016). This observation supports earlier suggestions in Japanese macaques that sons would leave their natal group as a function of their association with their mother (Itoigawa 1975). Similar findings on rhesus macaques, although based on a small sample, suggest that mother-son relationships between 2 and 3 years are predictive of the time of natal dispersal (Colvin 1986). Hence, mothers forming weaker bonds toward sons than daughters may contribute to promote male dispersal (cf. Timme 1995).

Finally, the stronger bonding between mothers and daughters is likely to promote female kin bonding and hence female philopatry (cf. Timme 1995). Previous studies have suggested a sex-bias in maternal behaviour in favour of the nondispersing sex, resulting in stronger bonds between the mother and offspring of the philopatric sex. Such maternal bias may even allow mothers to positively affect future reproductive success of the philopatric sex (see Clark 1978; Dittus 1979; Bulmer and Taylor 1980). Interestingly, this pattern reverses when females disperse, so that maternal behaviour is generally biased in favour of the non-dispersing sex. In chimpanzees (Pan troglodytes), for instance, mothers of sons are more gregarious than mothers of daughters (Murray et al. 2014), which likely promotes the social integration of sons, which stay permanently in their natal group. Given the fission-fusion system in chimpanzees, mothers might even directly influence access to social partners for their offspring, through the selection of particular subgroups (Lonsdorf et al. 2014). Likewise, in male-philopatric bonobos (Pan paniscus), bonding between mothers and sons may influence dominance rank and mating success of adult sons (Furuichi 1997; Surbeck et al. 2011).

In summary, existing studies suggest an important role of mothers in determining early social development in immatures. By selectively directing their affiliative and aggressive behaviours, mothers appear to determine the strength of future bonds with their offspring, facilitate male dispersal and foster daughters' integration in the maternal family.

\section{The role of fathers in offspring social development}

As female macaques mate promiscuously, paternity uncertainty is high (e.g. Manson 1992; Engelhardt et al. 2006; Dubuc et al. 2011, 2012; Ostner et al. 2013). Given this uncertainty, it seems unlikely to expect that male-infant bonds reflect paternity, unless males successfully mate-guard females and/or maximize their mating effort when the chance of fertilization is high (van Schaik and Paul 1996). Across macaques, however, female fertility signals vary from highly reliable (crested macaques, Macaca nigra: Higham et al. 2012) to being concealed to males (Assamese macaques, M. assamensis: Fürtbauer et al. 2011). In several macaque species, cues of fertility seem less precise, so that mate-guarding only partially matches female fertility, suggesting that in these species mateguarding alone may not efficiently ensure paternity certainty (e.g. rhesus macaques: Dubuc et al. 2012; but see Engelhardt et al. 2004 for an opposite example in long-tailed macaques, M. fascicularis).

Given these facts, it seems unlikely that male macaques generally recognize their offspring (e.g. based on their mating success with the mother), thus reducing the chances that fathers significantly contribute to the development of offspring sociality. However, it is possible that fathers recognize their offspring post-birth, for example through specific phenotypic cues (see Widdig et al. 2001; reviewed in Widdig 2007). Recent studies have shown that human raters (Kazem and Widdig 2013) and even untrained rhesus monkeys (Pfefferle et al. 2014a) can reliably use visual cues to detect paternal relatedness in rhesus faces alone, with parent-offspring resemblance increasing with offspring age (Kazem et al. 2018). It is therefore plausible that immatures and fathers may recognize each other, despite paternity being uncertain. Consequently, fathers can be expected to bias their behaviour toward their own offspring and by doing so positively affect 
their survival, but potentially also their social development. The evolution of male-infant bonds, at least father's presence and/or protection, should be favoured by selection, particularly in species with high risk of infanticide (van Schaik and Janson 2000). Given that mortality in macaques is considered highest within the first 2 years of their life (Dittus 1979; Blomquist 2013), both fathers and infants would enhance their fitness if male-infant bonds increase the chance of offspring survival (compare Kerhoas et al. 2016).

Primate studies on male-infant interactions have largely focused on baboons, reporting a behavioural bias of males towards their genetic offspring, with fathers providing protection, preferential access to food and spatial proximity (e.g. Buchan et al. 2003; Huchard et al. 2013; Onyango et al. 2013), while studies on macaques (particularly those with genetic paternity analysis) were more restricted and not conclusive. Male Barbary macaques, for instance, were shown to frequently handle infants, but not to preferentially interact with their genetic offspring (Kuester and Paul 1986; Paul et al. 1996). This result was confirmed in wild Barbary macaques, rejecting the mate-then-care (or paternal investment) hypothesis in this species (Ménard et al. 2001). However, the same study found that males providing infant care achieve higher mating success, supporting the care-then-mate hypothesis (Ménard et al. 2001). Similarly, genetic data in captive pigtail macaques suggested no preference in affiliation between fathers and offspring (Gust et al. 1996).

More evidence for paternal investment (although highly variable) was instead reported in captive rhesus macaques, where immatures selectively initiate associations with their fathers (Berenstain et al. 1981), and in free-ranging rhesus macaques, where immatures form persistent associations with specific males over the first 2 years of infancy (although paternity confirmation was lacking; Hill 1986). Finally, some troops of Japanese and stumptail macaques may also perform paternal care (including protection), but paternity in these studies was not confirmed by genetic analyses (Itani 1959; Gouzoules 1975; Smith and Peffer-Smith 1984).

More recent studies on free-ranging rhesus macaques, using genetic paternity analyses and longitudinal behavioural data from birth to sexual maturation, provide strong evidence that fathers are more likely to affiliate with their offspring, as compared to non-sires with unrelated infants (Langos et al. 2013). This bias is independent from the presence of the offspring's mother, suggesting that rhesus fathers preferentially interact with their offspring not simply to be closer to their mothers (Langos et al. 2013). The frequency of male-infant affiliation peaks at 2 years of age (Langos et al. 2013), matching the period when infant mortality is highest (Blomquist 2013). In contrast to previous studies, rhesus fathers preferentially initiate affiliation more than offspring do, especially toward sons (Langos et al. 2013). Possibly, this sex bias develops in response to the looser bonds that immature rhesus males have with their mothers (cf. Kulik et al. 2016), forcing them to bond with individuals outside of their maternal family. However, rhesus fathers appear to do little more than being affiliative in the first 2 years of infants' lives. For example, despite many opportunities, males fail to provide agonistic support toward their offspring, when they are involved in conflicts with other group members (Kulik et al. 2012), contrasting findings on yellow baboons, Papio cynocephalus, who bias their agonistic support towards genetic offspring (Buchan et al. 2003).

In a longitudinal study on wild Assamese macaques, genetic paternity predicted male-infant associations after weaning, although such paternal care might be facilitated by malefemale associations before weaning (Ostner et al. 2013). A recent study of the same population confirmed that these associations persist until the juvenile period is reached; however, infants maintain these bonds as they approach males more than vice versa. It was therefore suggested that infants actively seek male protection, and indeed, males provide agonistic support to immatures, which increases with the strength of their relationship (Minge et al. 2016).

While Assamese and rhesus macaques have a less pronounced skew in male reproduction, reproductive skew in male crested macaques is generally much higher (reviewed in Engelhardt et al. 2017). This indicates that high-ranking male crested macaques leave more offspring each, which might favour the formation of strong father-offspring bonds in this species. However, male crested macaques do not appear to form affiliative bonds with their offspring, at least not within the first year of life (Kerhoas et al. 2016). Given the intense male-male competition in this species, resulting in an extremely low mean alpha tenure of 12 months (Marty et al. 2017a), it is possible that males are selected to maximize their mating success rather than investing in bonds towards their genetic offspring. Nevertheless, despite absence of large predators, infant mortality in crested macaques reaches almost $20 \%$ in the first year of life (Engelhardt and PerwitasariFarajallah 2008). A study of infant survival revealed that take-overs in alpha male position are the best predictor of infant mortality in crested macaques (Kerhoas et al. 2014). Particularly, aggressive encounters may be highly risky for infants; hence, fathers might be especially responsive in these circumstances, rather than generally investing in affiliative bonds with offspring. Indeed, infant screams, signalling risk, trigger more responses in fathers than in unrelated males (D. Kerhoas et al. unpublished data).

Apart from affiliation or support, father's presence alone might be beneficial for immatures. A study on yellow baboons suggests that the presence of fathers in the same group at the age of maturation can accelerate infants' physiological maturation (Charpentier et al. 2008), for example because infants benefit from male tolerance at richer food patches (Huchard et al. 2013). If the presence of fathers can impact offspring 
fitness, the same might be true for the strength of fatheroffspring bonds. However, longitudinal data on rhesus macaques suggest rather weak and sex-specific effects (Langos et al. 2015). For example, immature rank and more affiliation with dominant males tend to increase female (but not male) offspring's body mass (Langos et al. 2015). On the other hand, body mass gain is higher for male (but not female) offspring, when affiliation is more evenly distributed across adult males. Similarly, co-residence with fathers during the first 4 years of life has no positive effect on the offspring's lifetime reproductive success, while the presence of mothers clearly has a significant impact (Langos et al. 2015).

In summary, results from macaques suggest that even in species with low paternity confidence, males bias some behaviours toward their genetic offspring, providing low-cost paternal care. However, fitness benefits of such care for immatures might be limited, suggesting that paternal care provided during offspring development may be marginal when compared to that of mothers, at least across macaques. Possibly, fathers provide fitness benefits through more indirect pathways (e.g. epigenetic inheritance through male germline), accounting for the variation in offspring physiology, metabolism, disease risk and social development (reviewed for mammals in Braun and Champagne 2014).

\section{The development of social interactions with maternal and paternal kin}

Given that kin share some proportions of their genes, kin selection theory predicts the evolution of social behaviours increasing the fitness among relatives (Hamilton 1964). As a consequence, kin are expected to preferentially affiliate and cooperate with each other as compared to unrelated group members. Given the matrilineal structure of macaque societies, females (and males up to natal dispersal) have maternal kin of various degrees available in their social group and, depending on the degree of male reproductive skew, the availability of paternal kin might even be higher (e.g. Widdig et al. 2004, 2016).

Indeed, there is broad evidence from different primate species, including macaques, that individuals form stronger affiliative bonds with related than unrelated individuals (e.g. Silk et al. 2006; Langergraber et al. 2007; reviewed in Silk 2002a). This is particular true for the philopatric sex, sharing a higher average relatedness than the dispersing sex (Altmann et al. 1996; de Ruiter and Geffen 1998). Among female philopatric macaques, adult females preferentially interact with close maternal kin (especially mother-daughters and maternal half-sibling dyads). Such preferences for close maternal kin are especially strong in despotic species such as rhesus, Japanese and pigtailed macaques (e.g. Kurland 1977; Massey 1977; Kapsalis and Berman 1996; Chapais et al. 1997;
Berman and Kapsalis 1999; Widdig et al. 2001, 2002; Schülke et al. 2013), but such preference (or less pronounced) can also be found in more tolerant species like bonnet macaques or moor macaques (Macaca maura) (Silk et al. 1981; Silk 1982; Matsumura 1998). Specifically, adult female bonnet macaques groom immature kin more than immatures of unrelated females (Silk et al. 1981). However, data from tolerant crested macaques reveal that adult females have more freedom in the formation of social bonds, with kin relationships suggested to be of lower importance (Duboscq et al. 2017).

The preference for close maternal kin as social partners is a shared characteristic among macaques as well as in other primates (e.g. Silk et al. 2006; Langergraber et al. 2007; reviewed in Silk 2002a). However, evidence accumulates that individuals of different primate species also favour paternal siblings as social partners (e.g. Smith et al. 2003; Silk et al. 2006; Charpentier et al. 2007; Lynch et al. 2017; Cords et al. 2018) even though paternal kin share a much lower degree of familiarity requiring other kin recognition mechanisms such as phenotype matching (reviewed in Widdig 2007). Similarly, adult female rhesus macaques preferentially interact in several behavioural contexts with paternal half sisters as compared to unrelated females (Widdig et al. 2001, 2002, 2006; Schülke et al. 2013). Given male reproduction is skewed and male breeding tenure tends to be relatively short across several macaque specis (reviewed in Widdig 2007), paternal siblings might be especially abundant and close in age (see Altmann 1979; Widdig 2013). Male reproductive skew influences the kin structure and hence the potential of the development of social bonds within groups of primates, as paternal relatedness (potentially in interaction with age proximity) can affect social relationships (see references above). Macaques are particularly interesting in this respect, as some evidence suggests that low levels of nepotism and high tolerance might be linked to male reproductive skew, a proxy of the 'hidden' paternal relatedness of a given species (Schülke and Ostner 2008). As such, future studies should test whether high levels of paternal relatedness indeed correspond to the presence of low maternal kin bias and high degree of social tolerance.

In the competitive context, kin selection theory further predicts that kin should direct less aggression to each other than towards unrelated individuals (Hamilton 1964). Depending upon the age difference of siblings, older siblings might influence the development of an infant and/or the motheroffspring relationship (Hooley and Simpson 1983). However, in adult rhesus macaques, for example, maternal half sisters share the highest rates of both affiliation and aggression, following mother-daughter dyads (Widdig et al. 2002). In contrast, paternal half sisters are significantly more affiliative than unrelated females, but they do not differ in rates of dyadic aggression (Widdig et al. 2002). However, 
adult female rhesus avoid targeting their paternal sisters when involved in agonistic conflicts (Widdig et al. 2006). Data on aggressive interactions in macaques are rare in the context of kinship, particularly for juvenile individuals, and previous studies on rhesus macaques provide no clear picture: some found a higher frequency of dyadic aggression by maternal kin, particularly directed at younger kin (Bernstein and Ehardt 1986) and infants born to low-ranking mothers (Berman 1980a), while others comparing rhesus and stump-tailed macaques ( $M$. arctoides) reported no differences in the frequency of aggression towards maternal kin and non-kin (de Waal and Luttrell 1989). However, aggression among kin seems less pronounced among bonnet macaques who direct severe aggression more towards unrelated than related individuals (Silk et al. 1981).

Only recently could we gain some more insights into the effect of both maternal and paternal relatedness on the development of social relationships in rhesus macaques (Kulik et al. 2015a, b; Widdig et al. 2016). Again, these studies consider the development of affiliative and aggressive behaviours covering the entire period from birth to sexual maturation. Starting with the first years of life, immature male and female rhesus form the strongest bonds with their maternal kin (Kulik et al. 2015a). The development of strong social bonds toward maternal kin by both males and females can be explained in terms of immatures being closely associated with their mothers, despite the sex difference in mother-offspring bonds reported (see Kulik et al. 2016); however, these bonds most likely optimize survival and sexual maturation during ontogeny. In particular, strong social bonds with maternal kin appear to have immediate benefits for daughters, apart from constituting the basis of their future social network as adults. Overall, infants' social network mirrors their mother's one throughout the first months of life, with infants especially engaged in positive social interactions with close kin (rather than distant kin or unrelated individuals) (de Waal 1996), particularly in top-ranking lineages (Berman 1982; see Ilany and Akçay 2016 on the social inheritance of animal social networks).

The development of social bonds toward paternal kin can also be explained by kin selection. Starting at the age of one, immature rhesus males (but not females) preferentially interact with paternal kin as compared to non-kin (Kulik et al. 2015a). These results suggest that at least male rhesus can discriminate paternal kin from an early age. Moreover, these findings indicate that male immatures, being less integrated in their maternal families (cf. Kulik et al. 2016), might have a stronger need to search for alternative social partners from early on. Loose integration of males within the maternal family, likely caused by the enhanced rate of aggression toward male immatures by both mothers (Kulik et al. 2016) and maternal sisters (Kulik et al. 2015b), might foster male immatures to look for alternative partners, like paternal kin or fathers, from earlier on (Langos et al. 2013). Interactions with paternally related age mates may be especially beneficial to male immatures, not only in the immediate term (being valuable social partners sharing the same genes within their natal group), but also in the longer term, as males leave their natal groups most likely with age mates, who are often paternal kin (Widdig et al. 2002). Forming social bonds with paternal kin might actually reduce dispersal costs of males, for example, by migrating with or into groups containing paternally related brothers (rhesus macaques: Albers and Widdig 2013; longtailed macaques: Gerber et al. 2016). Female immatures, in contrast, probably have to rely less on their paternal kin at this stage. Indeed, females remaining in their natal group usually have several maternal kin available and bonding with maternal kin might more likely enhance their fitness than bonding with paternal kin. Some evidence for this hypothesis comes from baboons. When both kin classes are available, females preferentially form bonds with maternal kin; however, once close maternal kin are not available anymore, adult females increase their bonds with paternal kin (Smith et al. 2003; Silk et al. 2006). A recent study on olive baboons (Papio hamadryas anubis) reports that immatures form stronger bonds with their paternal siblings when fathers are present in the group, suggesting that the development of such bonds is facilitated by the presence of the shared father (Lynch et al. 2017). These studies together with other studies in mandrills (Charpentier et al. 2007) suggest that immatures can discriminate paternal kin, which calls for more studies investigating the importance of paternal kin across macaques.

As mentioned earlier, stronger social bonds in primates have been reported among adult individuals of the philopatric sex compared to the dispersing sex (e.g. Strier et al. 2002; Slater et al. 2009; Cords et al. 2010). This was expected, given that individuals remaining in their natal group typically have a higher number of kin around, and kin are more likely to form stronger social bonds than unrelated individuals (reviewed in Silk 2002a). Interestingly, this bias in social bonds towards to philopatric sex holds true when kin availability does not yet differ. Analysis of kin patterns at the time of sexual maturation in macaques (approximately fourth year of life, i.e. before first maternity and natal dispersal) revealed that kin availability is still similar for both sexes. Consequently, at the time of sexual maturation, maternal kin are still the closest social partners for both sexes, but even more for philopatric females (Widdig et al. 2016). These findings suggest that sex differences in the development of sociality do not simply reflect kin availability but partially follow different developmental trajectories in the two sexes, which largely reflect adult patterns of social interactions.

As only female macaques remain in their natal group, they are more likely than males to compete with relatives (Silk et al. 1981). In addition, mothers are primarily responsible for offspring socialization (Bernstein and Ehardt 1986). Therefore, it 
was expected and found, at least in captive rhesus macaques, that females show a higher frequency of aggression toward maternal kin than males, particularly to younger once (Bernstein and Ehardt 1986). However, results from longitudinal data on the development of aggression in the same species revealed that the probability of initiating aggression is similar for both sexes, with both male and female immatures more frequently initiating aggressive interactions with maternal kin (as compared to paternal kin and non-kin) throughout development (Kulik et al. 2015b). Both males and females also have a higher probability to receive aggression from maternal kin until one and a half years of age, although males have a higher probability to receive aggression from paternal kin than non-kin, as compared to females. In contrast to affiliative behaviour, therefore, aggressive behaviour may only partially differ between sexes through development (Kulik et al. 2015b). This suggests that being aggressive might largely serve a similar function for both sexes during the first years of development, and aggressive behaviour does not necessarily anticipate adult patterns in the same way as affiliative behaviours do. While affiliative behaviour allows individuals to construct relationships over long-time frames, aggressive behaviour may serve a more immediate function, largely reflecting contingent needs (e.g. competition over resources; see Camilla and Fawcett 2018).

Overall, some patterns of social relationships of immature macaques already reflect adult patterns of social interactions. This is especially true for affiliative behaviours, which likely serves a longer-term function in building up relationships. Social interactions with maternal and paternal kin partially differ for males and females, and these differences increase through development as both sexes gradually grow into their social roles as adults, with males preparing for migration and females integrating more in their social network where they will spend the rest of their lives together with their offspring. In contrast, aggressive behaviour may have more direct consequences and likely serves a more immediate function, with minimal differences between male and female immatures.

\section{The effect of partner's sex and age on the development of sociality}

Depending on the partner's sex and age, immature male and female macaques may have dissimilar social preferences, enhancing sex-specific differences in the development of sociality. Previous studies have shown that immature female macaques are generally more engaged in social interactions than immature males, throughout development, while individuals of both sexes prefer to interact with same-sex partners (Japanese macaques: Eaton et al. 1985; Nakamichi 1989; long-tailed macaques: van Noordwijk et al. 1993; rhesus macaques: Kulik et al. 2015a). Longitudinal data covering the first 4 years of life of Japanese macaques revealed that immature males preferentially affiliate with males of similar age, while immature females prefer to socially interact with females of various age (Nakamichi 1989). A recent longitudinal study in rhesus macaques largely confirmed these findings, as immature females preferentially interact with other females, and immature males share more spatial proximity with females only in the first 2 years, but then preferentially interact with other males (Kulik et al. 2015a). Overall, these findings show that the philopatric sex forms stronger social bonds than the dispersing sex already prior to male dispersal and that these bonds are especially strong toward same-sex partners. Hence, sex differences in social relationships among immature macaques already mirror sex differences among adults (van Noordwijk et al. 1993).

In contrast, previous studies suggested that aggressive behaviour fails to anticipate adult behavioural patterns as much as affiliative behaviours do. For example, juveniles show no sex differences in aggressive behaviour (Japanese macaques: Eaton et al. 1986), although males around sexual maturation receive higher rates of aggression (rhesus macaques: Altmann 1962; Wilson and Boelkins 1970), becoming more aggressive than females when entering adulthood (Japanese macaques: Eaton et al. 1986). In contrast to females, who are largely aggressive toward kin throughout development, males receive less aggression by kin they live together when getting older (rhesus macaques: Bernstein and Ehardt 1986). Also, mothers' rank affects the rate of aggression received through development, with infants of high-ranking mothers being threatened less and receiving more protection than infants of low-ranking mothers (Berman 1980a). In rhesus macaques, infants receive aggression as early as a few months after their birth (Kulik et al. 2015b), when they start socializing with others (Kulik et al. 2015a). Interestingly, aggressive behaviour seems to be especially directed from older females toward male immatures, once again suggesting a lower level of male immatures' integration in their natal group (Kulik et al. 2015b).

Through development, immature macaques of both sexes seem to also preferentially affiliate with age peers (Nakamichi 1989; Kulik et al. 2015a). This is not surprising, as age proximity promotes social bonding in young macaques (e.g. Berman 1982; Janus 1989; Nakamichi 1989; Suomi 2005) and in adult macaques (e.g. Widdig et al. 2001). However, this may only be true for seasonal breeding species, as no preference for peers was detected among adult female crested macaques, which breed year round (Duboscq et al. 2017). Interestingly, preference for age peers is higher in males than in females, especially before male dispersal (Kulik et al. 2015a). In species with high male reproductive skew, age peers have a higher probability to share the same father, as male breeding tenure is generally short across species (Altmann 1979). Therefore, stronger bonds with age peers 
before dispersal might enhance the probability for males to migrate together with paternal kin (Widdig et al. 2004; Albers and Widdig 2013). Being loosely integrated in the maternal family and preferentially interacting with male peers who will likely migrate around the same time, male immatures might benefit from leaving their natal group together with closely bonded male peers (see Nakamichi 1989; Kulik et al. 2015a). In contrast, preferential interactions with peers, who might be paternal kin, do not seem to be as important for female immatures, at least not at this time of their life, given the strong maternal kin network available (Kulik et al. 2015a). As reproductive skew and male breeding tenure differ across primate species, future studies may reveal inter-specific differences in kin structure, kin preferences and mechanisms of kin recognition. In crested macaques with a high skew in paternity (Engelhardt et al. 2017) and short breeding tenure (Marty et al. 2017a), for instance, paternal kin might most likely be peers, potentially resulting in a kin preferences via age proximity only. In contrast, in species with a lower skew and more relaxed breeding tenure, such as rhesus macaques, paternal siblings are not only restricted to peers (Widdig et al. 2002), and other kin recognition mechanisms, such as phenotype matching, might have evolved (e.g. Pfefferle et al. 2014a, b).

Specific attention should be directed to social play, which is more frequent in primate males than females, across different life stages (e.g. rhesus macaques Brown and Dixson 2000; Japanese macaques Koyama 1985; Eaton et al. 1986; Nakamichi 1989; Assamese macaques Berghänel et al. 2015; reviewed in Fagen 1993; Roney and Maestripieri 2005). Indeed, social play is the only behaviour differing between sexes from the very first months of life, in rhesus macaques, being more frequent in males than females throughout development (Kulik et al. 2015a). It is especially interesting that these differences emerge so early in development. Given that play is a social arena in which individuals practice social behaviour and future adult skills (see e.g. Burghardt 2005; Kuczaj and Horback 2013; see Palagi 2018 in this Topical Collection), early sex differences in social play might trigger further sex differences in social behaviour. These differences in social play, in particular, might elicit different responses in group members, provide male and female infants with different experiences and thus also partially lead them to develop in different ways within the same social group (Kulik et al. 2015a; Palagi 2018 in this Topical Collection).

Importantly, longitudinal studies on Japanese and rhesus macaques found that immatures largely change their way to interact with other group members between 2 and 3 years of age (Nakamichi 1989; Kulik et al. 2015a, b). In rhesus macaques, these major developmental changes encompass all affiliative and aggressive behaviours but social play (Kulik et al. 2015a, b). Around 2 years of age, for instance, male immatures shift their social preferences toward male partners, while female immatures extend their social network to members other than peers (Kulik et al. 2015a). Moreover, major developmental changes in most social behaviours (i.e. grooming, proximity, aggression) appear around 2 years of age, when individuals drastically change their social partners or social behaviours reach a climax and then decrease again in intensity. Other studies have also found a similar peak in social interactions around this age, particularly in macaque species with similar life histories (e.g. Macaca fuscata: Eaton et al. 1986; Nakamichi 1989; Gunst et al. 2013; M. mulatta: Suomi 2005). This age period might therefore be a key milestone in the development of sociality in macaques. Around this age, immature macaques, like human adolescents (e.g. Liben et al. 2002; Blakemore et al. 2009; Negriff and Susman 2011; Beltz and Berenbaum 2013), might have acquired the behavioural patterns typical of adulthood, but might use them with different intensity. Through time, immatures would further refine their behaviours, with males and females following different developmental trajectories that best match their social roles as adults, adapting to the specific social structure they live in.

Overall, our review presents a dynamic picture of macaques' social development, which varies through age depending on the characteristics of the interaction partners. In particular, sex differences in social behaviour emerge early during development, and gradually increase through time, with a peak between 2 and 3 years of age. These differences increasingly reflect males' and females' social roles as adults (cf. Nakamichi and Yamada 2010), with males migrating into new groups, and thus preferentially interacting with male age peers, and females remaining in their natal group, and thus preferentially interacting with other females and especially with close maternal kin.

\section{Future directions}

Despite the existing study bias in favour of despotic macaque species (and particularly rhesus macaques), this review has allowed us to gain a closer view of the development of sociality across macaque species. To achieve a more complete picture on the social development of macaques, more longitudinal studies covering the years up to sexual maturation across a wider range of macaque species will be needed to better understand their socio-ecological diversity. Moreover, future studies should address other current limitations. First of all, it will be beneficial to better understand the complex interplay of aggressive and affiliative behaviours in the development of primate social bonding. For instance, the extent to which aggression negatively affects positive social interactions, in particular during development, is generally not clear in primates, as we do not understand whether aggression is generally directed toward social partners competing over the same resources, forming the strongest affiliative bonds, and/or simply being closer in space. Secondly, it is still not clear which factors cause some individuals to socialize more frequently than 
others, given that this is likely linked to higher fitness benefits in adulthood. Thirdly, although social bonding increases adults' fitness (Silk et al. 2003, 2009, 2010; Silk 2007; Schülke et al. 2010; Kulik et al. 2012; Langergraber et al. 2013; but see also Thompson and Cords 2018), little is known on the immediate effects of social bonds on infants' survival. Although social bonds likely have positive effects throughout primates' lives, the effects may vary across particular life history stages, with different social behaviours having a differential impact depending on the immatures' age. Fourthly, future studies should combine behavioural observations with a more experimental approach, to investigate psychological, emotional and physiological changes occurring in macaques between 2 and 3 years of age, and better understand whether these changes are comparable to those happening around puberty in humans. For instance, it would be interesting to understand whether more frequent social interactions provide specific benefits to immatures at this age, and if so, which ones. Moreover, future studies should better disentangle the potential effect of different bonding patterns (e.g. highly versus less social individuals) on dispersal and reproductive success, by analysing the long-term effects on social development in both female and male philopatric species. Finally, more comparative studies on the social development in other (Old world) primates are needed to determine the generality of these patterns or whether they are a unique characteristic of macaque societies.

Acknowledgments We thank the chief editors, Theo Bakker and James Traniello, for their support to the Topical Collection 'An evolutionary perspective on the development of primate sociality'. Furthermore, we are grateful to two reviewers and Peter Kappeler for constructive feedback on earlier versions of this manuscript.

Funding Information Open access funding provided by Max Planck Society.

\section{Compliance with ethical standards}

Conflict of interest The authors declare that they have no conflict of interest.

Open Access This article is distributed under the terms of the Creative Commons Attribution 4.0 International License (http:// creativecommons.org/licenses/by/4.0/), which permits unrestricted use, distribution, and reproduction in any medium, provided you give appropriate credit to the original author(s) and the source, provide a link to the Creative Commons license, and indicate if changes were made.

\section{References}

Albers M, Widdig A (2013) The influence of kinship on familiar natal migrant rhesus macaques (Macaca mulatta). Int J Primatol 34:99114

Altmann SA (1962) A field study of the sociobiology of rhesus monkeys, Macaca mulatta. Ann N Y Acad Sci 102:338-435
Altmann J (1979) Age cohorts as paternal sibships. Behav Ecol Sociobiol 6:161-164

Altmann J, Alberts SC, Haines SA, Dubach J, Muruthi P, Coote T, Geffen E, Cheesman DJ, Mututua RS, Saiyalel SN, Wayne RK, Lacy RC, Bruford MW (1996) Behavior predicts genetic structure in a wild primate group. Proc Natl Acad Sci U S A 93:5797-5801

Bardi M, Huffman MA (2002) Effects of maternal style on infant behavior in Japanese macaques (Macaca fuscata). Dev Psychobiol 41: 364-372

Bentley-Condit VK (2003) Sex Differences in Captive Olive Baboon Behavior During the First Fourteen Days of Life. Int J Primatol 24:1093-1112

Beltz AM, Berenbaum SA (2013) Cognitive effects of variations in pubertal timing: is puberty a period of brain organization for human sex-typed cognition? Horm Behav 63:823-828

Bercovitch FB, Widdig A, Andrea Trefilov MJ, Kessler JD, Berard JS, Nürnberg P, Krawczak M (2003) A longitudinal study of age-specific reproductive output and body condition among male rhesus macaques, Macaca mulatta. Naturwissenschaften 90(7):309-312

Berenstain L, Rodman PS, Smith DG (1981) Social relations between fathers and offspring in a captive group of rhesus monkeys (Macaca mulatta). Anim Behav 29:1057-1063

Berghänel A, Schülke O, Ostner J (2015) Locomotor play drives motor skill acquisition at the expense of growth: a life history trade-off. Sci Adv 1:e1500451

Berkman LF, Glass T (2000) Social integration, social networks, social support, and health. In: Berkman LF, Kawachi I (eds) Social epidemiology. Oxford University Press, New York, pp 137-173

Berkman LF, Melchior M, Chastang JF, Niedhammer I, Leclerc A, Goldberg M (2004) Social integration and mortality: a prospective study of French employees of Electricity of France-Gas of France: the GAZEL cohort. Am J Epidemiol 159:167-174

Berman CM (1980a) Early agonistic experience and rank acquisition among free-ranging infant rhesus monkeys. Int J Primatol 1:153170

Berman CM (1980b) Mother-infant relationships among free-ranging rhesus monkeys on Cayo Santiago: a comparison with captive pairs. Anim Behav 28:860-873

Berman CM (1982) The ontogeny of social relationships with group companions among free-ranging infant rhesus monkeys I. Social networks and differentiation. Anim Behav 30:149-162

Berman CM (1992) Immature siblings and mother-infant relationships among free-ranging rhesus monkeys on Cayo Santiago. Anim Behav 44:247-258

Berman CM, Kapsalis E (1999) Development of kin bias among rhesus monkeys: maternal transmission or individual learning? Anim Behav 58:883-894

Bernstein IS, Ehardt CL (1985) Age-sex differences in the expression of agonistic behavior in rhesus monkey (Macaca mulatta) groups. J Comp Psychol 99:115-132

Bernstein IS, Ehardt CL (1986) The influence of kinship and socialization on aggressive behaviour in rhesus monkeys (Macaca mulatta). Anim Behav 34:739-747

Blakemore JEO, Berenbaum SE, Liben LS (2009) Gender development. Psychology Press, New York

Blomquist GE (2013) Maternal effects on offspring mortality in rhesus macaques (Macaca mulatta). Am J Primatol 75:238-251

Braun K, Champagne FA (2014) Paternal influences on offspring development: behavioural and epigenetic pathways. J Neuroendocrinol 26:697-706

Brown GR, Dixson AF (2000) The development of behavioural sex differences in infant rhesus macaques (Macaca mulatta). Primates 41: 63-77

Buchan JC, Alberts SC, Silk JB, Altmann J (2003) True paternal care in a multi-male primate society. Nature 425:179-181 
Bulmer MG, Taylor PD (1980) Dispersal and the sex ratio. Nature 284(5755):448-449

Burghardt GM (2005) The genesis of animal play: testing the limits. The MIT Press, Cambridge, MA

Cacioppo JT, Hawkley LC (2003) Social isolation and health, with an emphasis on underlying mechanisms. Perspect Biol Med 46:S39 S52

Camilla Cenni TW, Fawcett JW (2018) The coevolution of juvenile playfighting and adult competition. Ethology 124(5):290-301

Chapais B, Gauthier C, Prud'Homme J, Vasey P (1997) Relatedness threshold for nepotism in Japanese macaques. Anim Behav 53: 1089-1101

Charpentier MJE, Peignot P, Hossaert-Mckey M, Wickings EJ (2007) Kin discrimination in juvenile mandrills, Mandrillus sphinx. Anim Behav 73:37-45

Charpentier M, Van Horn RC, Altmann J, Alberts SC (2008) Paternal effects on offspring fitness in a multimale primate society. Proc Natl Acad Sci U S A 105:1988-1992

Clark AB (1978) Sex Ratio and Local Resource Competition in a Prosimian Primate. Science 201(4351):163-165

Clutton-Brock TH, Lukas D (2012) The evolution of social philopatry and dispersal in female mammals. Mol Ecol 21:472-492

Colvin JD (1986) Proximate causes of male emigration at puberty in rhesus macaques. In: Rawlins RG, Kessler MJ (eds) The Cayo Santiago macaques. History, behavior and biology. State University of New York Press, Albany, pp 131-157

Cooper MA, Bernstein IS (2000) Social grooming in assamese macaques (Macaca assamensis). Am J Primatol 50:77-85

Cords M, Sheehan MJ, Ekernas LS (2010) Sex and age differences in juvenile social priorities in female philopatric, nondespotic blue monkeys. Am J Primatol 72:193-205

Cords M, Minich T, Roberts S-J, Sleator C (2018) Evidence for paternal kin bias in the social affiliation of adult female blue monkeys. Am J Primatol 80:e22761

Crespi B, Semeniuk C (2004) Parent-offspring conflict in the evolution of vertebrate reproductive mode. Am Nat 163:635-653

Crockford C, Wittig RM, Whitten PL, Seyfarth RM, Cheney DL (2008) Social stressors and coping mechanisms in wild female baboons (Papio hamadryas ursinus). Horm Behav 53:254-265

de Ruiter JR, Geffen E (1998) Relatedness of matrilines, dispersing males and social groups in long-tailed macaques (Macaca fascicularis). Proc R Soc Lond B 265:79-87

de Waal FBM (1996) Macaque social culture: development and perpetuation of affiliative networks. J Comp Psychol 110:147-154

de Waal FBM, Luttrell LM (1989) Toward a comparative socioecology of the genus Macaca: different dominance styles in rhesus and stumptail monkeys. Am J Primatol 19:83-109

Di Fiore A (2003) Molecular genetic approaches to the study of primate behavior, social organization, and reproduction. Am J Phys Anthropol 122:62-99

Dittus WPJ (1979) The evolution of behaviors regulating density and agespecific sex ratios in a primate population. Behaviour 69:265-301

Dixson AF, Nevison CM (1997) The socioendocrinology of adolescent development in male rhesus monkeys (Macaca mulatta). Horm Behav 31:126-135

Duboscq J, Neumann C, Agil M, Perwitasari-Farajallah D, Thierry B, Engelhardt A (2017) Degrees of freedom in social bonds of crested macaque females. Anim Behav 123:411-426

Dubuc C, Muniz L, Heistermann M, Engelhardt A, Widdig A (2011) Testing the priority-of-access model in a seasonally breeding primate species. Behav Ecol Sociobiol 65:1615-1627

Dubuc C, Muniz L, Heistermann M, Widdig A, Engelhardt A (2012) Do males time their mate-guarding effort with the fertile phase in order to secure fertilisation in Cayo Santiago rhesus macaques? Horm Behav 61:696-705
Eaton GG, Johnson DF, Glick BB, Worlein JM (1985) Development in Japanese macaques (Macaca fuscata): sexually dimorphic behavior during the first year of life. Primates 26:238-247

Eaton GG, Johnson DF, Glick BB, Worlein JM (1986) Japanese macaques (Macaca fuscata) social development: sex differences in juvenile behavior. Primates 27:141-150

Ellis L, Hershberger S, Field E, Wersinger S, Pellis S, Geary D, Palmer C, Hoyenga K, Hetsroni A, Karadi K (2013) Sex differences: summarizing more than a century of scientific research. Psychology Press, New York

Engelhardt A, Perwitasari-Farajallah D (2008) Reproductive biology of Sulawesi crested black macaques (Macaca nigra). Folia Primatol 79:326

Engelhardt A, Pfeifer JB, Heistermann M, Niemitz C, van Hooff JARAM, Hodges JK (2004) Assessment of female reproductive status by male longtailed macaques, Macaca fascicularis, under natural conditions. Anim Behav 67:915-924

Engelhardt A, Heistermann M, Hodges JK, Nuernberg P, Niemitz C (2006) Determinants of male reproductive success in wild longtailed macaques (Macaca fascicularis) - male monopolisation, female mate choice or post-copulatory mechanisms? Behav Ecol Sociobiol 59:740-752

Engelhardt A, Muniz L, Perwitasari-Farajallah D, Widdig A (2017) Highly polymorphic microsatellite markers for the assessment of male reproductive skew and genetic variation in critically endangered crested macaques (Macaca nigra). Int J Primatol 38:672-691

Engh AL, Beehner JC, Bergman TJ, Whitten PL, Hoffmeier RR, Seyfarth RM, Cheney DL (2006a) Behavioural and hormonal responses to predation in female chacma baboons (Papio hamadryas ursinus). Proc R Soc Lond B 273:707-712

Engh AL, Beehner JC, Bergman TJ, Whitten PL, Hoffmeier RR, Seyfarth RM, Cheney DL (2006b) Female hierarchy instability, male immigration and infanticide increase glucocorticoid levels in female chacma baboons. Anim Behav 71:1227-1237

Eriksson BG, Hessler RM, Sundh V, Steen B (1999) Cross-cultural analysis of longevity among Swedish and American elders: the role of social networks in the Gothenburg and Missouri longitudinal studies compared. Arch Gerontol Geriat 28:131-148

Estrada A, Estrada R (1976) Birth and breeding cyclicity in an outdoor living stumptail macaque (Macaca arctoides) group. Primates 17: 225-231

Fagen R (1993) Primate juveniles and primate play. In: Pereira ME, Fairbanks LA (eds) Juvenile primates: life history, development and behavior. Oxford University Press, Chicago, IL, pp 182-196

Fraser ON, Schino G, Aureli F (2008) Components of relationship quality in chimpanzees. Ethology 114:834-843

Fürtbauer I, Heistermann M, Schülke O, Ostner J (2011) Concealed fertility and extended female sexuality in a non-human primate (Macaca assamensis). PLoS One 6:e23105

Furuichi T (1997) Agonistic interactions and matrifocal dominance rank of wild bonobos (Pan paniscus) at Wamba. Int J Primatol 18:855875

Gerber L, Krützen M, de Ruiter JR, van Schaik CP, van Noordwijk MA (2016) Postdispersal nepotism in male long-tailed macaques (Macaca fascicularis). Ecol Evol 6:46-55

Godfray HCJ (1995) Evolutionary theory of parent offspring conflict. Nature 376:133-138

Gouzoules H (1975) Maternal rank and early social interactions of infant stumptail macaques, Macaca arctoides. Primates 16:405-418

Gouzoules S, Gouzoules H (1987) Kinship. In: Smuts BB, Cheney DL, Seyfarth RM, Wrangham RW, Struhsaker TT (eds) Primate societies. University of Chicago Press, Chicago, IL, pp 299-305

Gunst N, Leca J-B, Vasey PL (2013) Development of sexual and sociosexual behaviours in free-ranging juvenile male Japanese macaques, Macaca fuscata. Behaviour 150:1225-1254 
Gust DA, Gordon TP, Gergits WF, Casna NJ, Gould KG, McClure HM (1996) Male dominance rank and offspring-initiated affiliative behaviors were not predictors of paternity in a captive group of pigtail macaques (Macaca nemestrina). Primates 37:271-278

Hamilton WD (1964) The genetical evolution of social behaviour I/II. J Theor Biol 7:1-52

Higham JP, Heistermann M, Saggau C, Agil M, Perwitasari-Farajallah D, Engelhardt A (2012) Sexual signalling in female crested macaques and the evolution of primate fertility signals. BMC Evol Biol 12:89

Hill DA (1986) Social relationships between adult male and immature rhesus macaques. Primates 27(4):425-440

Hinde RA, Simpson MJA (1975) Qualities of mother-infant relationships in monkeys. In: Ciba Foundation Symposium 33-Parent-Infant Interaction. John Wiley \& Sons, New York, pp 39-67

Hinde RA, Spencer-Booth Y (1967) The behaviour of socially living rhesus monkeys in their first two and a half years. Anim Behav 15:169-196

Holt-Lunstad J, Smith TB, Layton JB (2010) Social relationships and mortality risk: a meta-analytic review. PLoS Med 7:e1000316

Hooley JM (1983) Primiparous and multiparous mothers and their infants. In: Hinde R (ed) In primate social relationships an integrated approach. Blackwell, Oxford, pp 142-145

Hooley JM, Simpson MJA (1983) Influence of siblings on the infant's relationships with the mother and others. In: Hinde R (ed) In Primate Social Relationships an Integrated Approach. Blackwell, Oxford, pp 139-142

Huchard E, Charpentier MJ, Marshall H, King AJ, Knapp LA, Cowlishaw G (2013) Paternal effects on access to resources in a promiscuous primate society. Behav Ecol 24:229-236

Ilany A, Akçay E (2016) Social inheritance can explain the structure of animal social networks. Nat Commun 7:12084

Itani J (1959) Paternal care in the wild Japanese monkey, Macaca fuscata fuscata. Primates 2:61-93

Itoigawa N (1973) Group organization of a natural troop of Japanese monkeys and mother-infant interactions. In: Carpenter CR (ed) Behavioral regulators of behavior in primates. Bucknell University Press, Lewisburg, pp 229-243

Itoigawa N (1975) Variables in male leaving a group of Japanese macaques. In: Proceedings from the Symposia of the Fifth Congress of the International Primatological Society, Nagoya, Japan, August 1974, pp 233-245

Janus M (1989) Reciprocity in play, grooming, and proximity in sibling and nonsibling young rhesus monkeys. Int J Primatol 10:243-261

Kappeler PM, Cremer S, Nunn CL (2015) Sociality and health: impacts of sociality on disease susceptibility and transmission in animal and human societies. Philos Trans R Soc, B Biol Sci 370(1669): 20140116-20140116

Kapsalis E, Berman CM (1996) Models of affiliative relationships among free-ranging rhesus monkeys (Macaca mulatta). II. Testing predictions for three hypothesized organizing principles. Behaviour 133: $1235-1263$

Kazem AJN, Widdig A (2013) Visual phenotype matching: cues to paternity are present in rhesus macaque faces. PLoS One 8:e55846

Kazem AJN, Barth Y, Pfefferle D, Kulik L, Widdig A (2018) Parentoffspring facial resemblance increases with age in rhesus macaques. Proc R Soc B 285:20181208

Kerhoas D, Perwitasari-Farajallah D, Agil M, Widdig A, Engelhardt A (2014) Social and ecological factors influencing offspring survival in wild macaques. Behav Ecol 25(5):1164-1172

Kerhoas D, Kulik L, Perwitasari-Farajallah D, Agil M, Engelhardt A, Widdig A (2016) Mother-male bond, but not paternity, influences male-infant affiliation in wild crested macaques. Behav Ecol Sociobiol 70:1117-1130

Koyama N (1985) Playmate relationships among individuals of the Japanese monkey troop in Arashiyama. Primates 26:390-406
Kuczaj SA, Horback KM (2013) Play and emotion. In: Watanabe S, Kuczaj SA (eds) Emotions of animals and humans: comparative perspectives. Springer, Tokyo, pp 87-112

Kuester J, Paul A (1986) Male-infant relationships in semifree-ranging Barbary macaques (Macaca sylvanus) of affenberg salem/FRG: testing the "male care" hypothesis. Am J Primatol 10:315-327

Kulik L, Muniz L, Mundry R, Widdig A (2012) Patterns of interventions and the effect of coalitions and sociality on male fitness. Mol Ecol 21:699-714

Kulik L, Amici F, Langos D, Widdig A (2015a) Sex differences in the development of social relationships in rhesus macaques (Macaca mulatta). Int J Primatol 36:353-376

Kulik L, Amici F, Langos D, Widdig A (2015b) Sex differences in the development of aggressive behavior in rhesus macaques (Macaca mulatta). Int J Primatol 36:764-789

Kulik L, Langos D, Widdig A (2016) Mothers make a difference: mothers develop weaker bonds with immature sons than daughters. PLoS One 11:e 0154845

Kurland JA (1977) Kin selection in Japanese monkeys. Contrib Primatol 12:1-145

Langergraber K, Mitani J, Vigilant L (2007) The limited impact of kinship on cooperation in wild chimpanzees. Proc Natl Acad Sci U S A 104:7786-7790

Langergraber KE, Mitani JC, Watts DP, Vigilant L (2013) Male-female socio-spatial relationships and reproduction in wild chimpanzees. Behav Ecol Sociobiol 67:861-873

Langos D, Kulik L, Mundry R, Widdig A (2013) The impact of paternity on male-infant association in a primate with low paternity certainty. Mol Ecol 22:3638-3651

Langos D, Kulik L, Ruiz-Lambides A, Widdig A (2015) Does male care, provided to immature individuals, influence immature fitness in rhesus macaques? PLoS One 10:e137841

Lee PC (1984) Early infant development and maternal care in free-ranging vervet monkeys. Primates 25(1):36-47

Liben LS, Susman EJ, Finkelstein JW, Chinchilli VM, Kunselman S, Schwab J, Semon Dubas J, Demers LM, Lookingbill G, D'Arcangelo MR, Krogh HR, Kulin HE (2002) The effects of sex steroids on spatial performance: a review and an experimental clinical investigation. Dev Psychol 38:236-253

Lonsdorf EV (2017) Sex differences in nonhuman primate behavioral development. J Neurosci Res 95:213-221

Lonsdorf EV, Ross SR (2012) Socialization and Development of Behavior. In: Mitani JC, Call J, Kappeler PM, Palombit RA, Silk JB (eds) The Evolution of Primate Societies. University of Chicago Press, Chicago, IL, pp 245-268

Lonsdorf EV, Anderson KE, Stanton MA, Shender M, Heintz MR, Goodall J, Murray CM (2014) Boys will be boys: sex differences in wild infant chimpanzee social interactions. Anim Behav 88:7983

Lynch EC, Fiore AD, Lynch RF, Palombit RA (2017) Fathers enhance social bonds among paternal half-siblings in immature olive baboons (Papio hamadryas anubis). Behav Ecol Sociobiol 71:120

Maestripieri D (1994a) Costs and benefits of maternal aggression in lactating female rhesus macaques. Primates 35:443-453

Maestripieri D (1994b) Social structure, infant handling, and mothering styles in group-living old world monkeys. Int J Primatol 15:531-553

Maestripieri D (1994c) Mother-infant relationships in three species of macaques (Macaca mulatta, M. nemestrina, M. arctoides). I. Development of the mother-infant relationship in the first three months. Behaviour 131:75-96

Maestripieri D (2018) Maternal influences on primate social development. Behav Ecol Sociobiol 72:130

Manson JH (1992) Measuring female mate choice in Cayo Santiago rhesus macaques. Anim Behav 44:405-416 
Marty PR, Hodges K, Agil M, Engelhardt A (2017a) Alpha male replacements and delayed dispersal in crested macaques (Macaca nigra). Am J Primatol 79:e22448

Marty PR, Hodges K, Heistermann M, Agil M, Engelhardt A (2017b) Is social dispersal stressful? A study in male crested macaques (Macaca nigra). Horm Behav 87:62-68

Massey A (1977) Agonistic aids and kinship in a group of pigtail macaques. Behav Ecol Sociobiol 2:31-40

Matsumura S (1998) Relaxed dominance relations among female moor macaques (Macaca maurus) in their natural habitat, South Sulawesi, Indonesia. Folia Primatol 69:346-356

Ménard N, Segesser F, Scheffrahn W, Pastorini J, Vallet D, Gaci B, Martin RD, Gautier-Hion A (2001) Is male-infant caretaking related to paternity and/or mating activities in wild Barbary macaques (Macaca sylvanus)? Cr Acad Sci III-Vie 324:601-610

Meredith SL (2013) Identifying Proximate and Ultimate Causation in the Development of Primate Sex-Typed Social Behavior. In: KBH C, Hinde K, Rutherford JN (eds) Building Babies: Primate Development in Proximate and Ultimate Perspective. Springer New York, New York, NY, pp 411-433

Minge C, Berghänel A, Schülke O, Ostner J (2016) Patterns and Consequences of Male-Infant Relationships in Wild Assamese Macaques (Macaca assamensis). Int J Primatol 37:350-370

Missakian EA (1974) Mother-offspring grooming relations in rhesus monkeys. Arch Sex Behav 3:135-141

Murray CM, Lonsdorf EV, Stanton MA, Wellens KR, Miller JA, Goodall J, Pusey AE (2014) Early social exposure in wild chimpanzees: mothers with sons are more gregarious than mothers with daughters. Proc Natl Acad Sci U S A 111:18189-18194

Nakamichi M (1989) Sex differences in social development during the first 4 years in a free-ranging group of Japanese monkeys, Macaca fuscata. Anim Behav 38:737-748

Nakamichi M (2001) Mother-offspring relationship in macaques. In: Matsuzawa T (ed) Primate origins of human cognition and behavior. Springer, Tokyo, pp 418-440

Nakamichi M, Yamada K (2010) Lifetime social development in female Japanese macaques. In: Nakagawa N, Nakamichi M, Sugiura H (eds) The Japanese macaques. Primatology monographs. Springer, Tokyo, pp 241-270

Negriff S, Susman EJ (2011) Pubertal timing, depression, and externalizing problems: a framework, review, and examination of gender differences. J Res Adolesc 21:717-746

Nguyen N, Gesquiere L, Alberts SC, Altmann J (2012) Sex differences in the mother-neonate relationship in wild baboons: social, experiential and hormonal correlates. Anim Behav 83:891-903

Olsen RB, Olsen JF, Gunner-Svensson F, Waldstrøm B (1991) Social networks and longevity. A 14 year follow-up study among elderly in Denmark. Soc Sci Med 33:1189-1195

Onyango PO, Gesquiere LR, Altmann J, Alberts SC (2013) Testosterone positively associated with both male mating effort and paternal behavior in savanna baboons (Papio cynocephalus). Horm Behav 63: $430-436$

Ostner J, Vigilant L, Bhagavatula J, Franz M, Schülke O (2013) Stable heterosexual associations in a promiscuous primate. Anim Behav $86: 623-631$

Palagi E (2018) Not just for fun! Social playas a springboard for adult social competence in human and non-human primates. Behav Ecol Sociobiol 72:90

Paul A, Kuester J, Arnemann J (1996) The sociobiology of male-infant interactions in Barbary macaques, Macaca sylvanus. Anim Behav $51: 155-170$

Pereira ME, Altmann J (1985) Development of social behavior in freeliving nonhuman primates. In: Watts ES (ed) Nonhuman primate models for human growth and development. Alan R. Liss, New York, pp 217-309
Pfefferle D, Kazem AJN, Brockhausen RR, Ruiz-Lambides AV, Widdig A (2014a) Monkeys spontaneously discriminate their unfamiliar paternal kin under natural conditions using facial cues. Curr Biol 24:1806-1810

Pfefferle D, Ruiz-Lambides AV, Widdig A (2014b) Female rhesus macaques discriminate unfamiliar paternal sisters in playback experiments - support for acoustic phenotype matching. Proc R Soc B 281:20131628

Roney JR, Maestripieri D (2005) Social development and affiliation. In: Maestripieri D (ed) Primate psychology. Harvard University Press, Cambridge, pp 171-204

Schino G, D'Amato FR, Troisi A (1995) Mother-infant relationships in Japanese macaques: sources of inter-individual variation. Anim Behav 49:151-158

Schino G, Speranza L, Troisi A (2001) Early maternal rejection and later social anxiety in juvenile and adult Japanese macaques. Dev Psychobiol 38:186-190

Schülke O, Ostner J (2008) Male reproductive skew, paternal relatedness, and female social relationships. Am J Primatol 70:695-698

Schülke O, Ostner J (2012) Ecological and social influences on sociality. In: Mitani JC, Call J, Kappeler PM, Palombit RA, Silk JB (eds) The evolution of primate societies. University of Chicago Press, Chicago, IL, pp 193-219

Schülke O, Bhagavatula J, Vigilant L, Ostner J (2010) Social bonds enhance reproductive success in male macaques. Curr Biol 20: $2207-2210$

Schülke O, Wenzel S, Ostner J (2013) Paternal relatedness predicts the strength of social bonds among female rhesus macaques. PLoS One 8:e59789

Sear R, Gibson MA, Hinde K (2009) Richer milk for sons but more milk for daughters: Sexbiased investment during lactation varies with maternal life history in rhesus macaques. Am J Hum Biol 21(4): 512-519

Silk JB (1982) Altruism among female Macaca radiata: explanations and analysis of patterns of grooming and coalition formation. Behaviour 79:162-188

Silk JB (2002a) Kin selection in primate groups. Int J Primatol 23:849 875

Silk JB (2002b) Using the 'F'-word in primatology. Behaviour 139:421446

Silk JB (2007) The adaptive value of sociality in mammalian groups. Philos Trans R Soc B 362:539-559

Silk JB, Samuels A, Rodman PS (1981) The influence of kinship, rank, and sex on affiliation and aggression between adult female and immature bonnet macaques (Macaca radiata). Behaviour 78:111137

Silk JB, Alberts SC, Altmann J (2003) Social bonds of female baboons enhance infant survival. Science 302:1231-1234

Silk JB, Altmann J, Alberts SC (2006) Social relationships among adult female baboons (Papio cynocephalus) I. Variation in the strength of social bonds. Behav Ecol Sociobiol 61:183-195

Silk JB, Beehner JC, Bergman TJ, Crockford C, Engh AL, Moscovice LR, Wittig RM, Seyfarth RM, Cheney DL (2009) The benefits of social capital: close social bonds among female baboons enhance offspring survival. Proc R Soc Lond B 276:3099-3104

Silk JB, Beehner JC, Bergman TJ, Crockford C, Engh AL, Moscovice LR, Wittig RM, Seyfarth RM, Cheney DL (2010) Strong and consistent social bonds enhance the longevity of female baboons. Curr Biol 20:1359-1361

Slater KY, Schaffner CM, Aureli F (2009) Sex differences in the social behavior of wild spider monkeys (Ateles geoffroyi yucatanensis). Am J Primatol 71:21-29

Smith EO (1984) Non-seasonal breeding patterns in stumptail macaques (Macaca arctoides). Primates 25:117-122

Smith KP, Christakis NA (2008) Social networks and health. Annu Rev Sociol 34:405-429 
Smith EO, Peffer-Smith PG (1984) Adult male-immature interactions in captive stumptail macaques (Macaca arctoides). In: Taub DM (ed) Primate paternalism. Van Nostrand Reinhold, New York, pp 88-112

Smith KL, Alberts SC, Altmann J (2003) Wild female baboons bias their social behaviour towards paternal half-sisters. Proc R Soc Lond B 270:503-510

Strier KB, Dib LT, Figueira JEC (2002) Social dynamics of male muriquis (Brachyteles arachnoides hypoxanthus). Behaviour 139: 315-342

Suomi SJ (2005) Mother-infant attachment, peer relationships, and the development of social networks in rhesus monkeys. Hum Dev 48: $67-79$

Surbeck M, Mundry R, Hohmann G (2011) Mothers matter! Maternal support, dominance status and mating success in male bonobos (Pan paniscus). Proc R Soc Lond B 278:590-598

Tanaka I (1989) Variability in the development of mother-infant relationships among free-ranging Japanese macaques. Primates 30:477-491

Thierry B (1985) Social development in three species of macaque (Macaca mulatta, M. fascicularis, M. tonkeana): a preliminary report on the first ten weeks of life. Behav Process 11:89-95

Thierry B (2000) Covariation of conflict management patterns in macaque societies. In: Aureli F, de Waal FBM (eds) Natural conflict resolution. University of California Press, Berkeley, pp 106-128

Thierry B (2007) Unity in diversity: lessons from macaque societies. Evol Anthropol 16:224-238

Thompson NA, Cords M (2018) Stronger social bonds do not always predict greater longevity in a gregarious primate. Ecol Evol 8: 1604-1614

Timme A (1995) Sex differences in infant integration in a semifreeranging group of Barbary macaques (Macaca sylvanus) at Salem, Germany. Am J Primatol 37:221-231

van Noordwijk MA, Hemelrijk CK, Herremans LAM, Sterck EHM (1993) Spatial position and behavioral sex differences in juvenile long-tailed macaques. In: Pereira ME, Fairbanks LA (eds) Juvenile primates: life history, development and behavior. University of Chicago Press, Chicago, IL, pp 77-85

van Schaik CP, Janson CH (eds) (2000) Infanticide by males and its implications. Cambridge University Press, Cambridge

van Schaik CP, Paul A (1996) Male care in primates: does it ever reflect paternity? Evol Anthropol 5:152-156
Widdig A (2007) Paternal kin discrimination: the evidence and likely mechanisms. Biol Rev 82:319-334

Widdig A (2013) The impact of male reproductive skew on kin structure and sociality in multi-male groups. Evol Anthropol 22:239-250

Widdig A, Nürnberg P, Krawczak M, Streich WJ, Bercovitch FB (2001) Paternal relatedness and age proximity regulate social relationships among adult female rhesus macaques. Proc Natl Acad Sci U S A 98: 13769-13773

Widdig A, Nürnberg P, Krawczak M, Streich WJ, Bercovitch FB (2002) Affiliation and aggression among adult female rhesus macaques: a genetic analysis of paternal cohorts. Behaviour 139:371-391

Widdig A, Bercovitch FB, Streich WJ, Sauermann U, Nürnberg P, Krawczak M (2004) A longitudinal analysis of reproductive skew in male rhesus macaques. Proc R Soc Lond B 271:819-826

Widdig A, Streich WJ, Nürnberg P, Croucher PJP, Bercovitch FB, Krawczak M (2006) Paternal kin bias in the agonistic interventions of adult female rhesus macaques (Macaca mulatta). Behav Ecol Sociobiol 61:205-214

Widdig A, Langos D, Kulik L (2016) Sex differences in kin bias at maturation: male rhesus macaques prefer paternal kin prior to natal dispersal. Am J Primatol 78:78-91

Wilson AP, Boelkins RC (1970) Evidence for seasonal variation in aggressive behaviour by Macaca mulatta. Anim Behav 18:719-724

Wittig RM, Crockford C, Lehmann J, Whitten PL, Seyfarth RM, Cheney DL (2008) Focused grooming networks and stress alleviation in wild female baboons. Horm Behav 54:170-177

Worlein JM, Eaton GG, Johnson DF, Glick BB (1988) Mating season effects on mother-infant conflict in Japanese macaques, Macaca fuscata. Anim Behav 36:1472-1481

Young C, Majolo B, Heistermann M, Schülke O, Ostner J (2014) Responses to social and environmental stress are attenuated by strong male bonds in wild macaques. Proc Natl Acad Sci 111(51): 18195-18200

Zehr JL, Meter PEV, Wallen K (2005) Factors regulating the timing of puberty onset in female rhesus monkeys (Macaca mulatta): role of prenatal androgens, social rank, and adolescent body weight. Biol Reprod 72:1087-1094

Publisher's Note Springer Nature remains neutral with regard to jurisdictional claims in published maps and institutional affiliations. 